ESJ Humanities

\title{
Juxtaposing Physical and Recreational Activities with Satisfaction with Life - A Case Study of Female Academics in Obafemi Awolowo University, Nigeria
}

\author{
Afolaremi Bamkole Bamgbopa \\ Dr. Adejoke Clara Babalola \\ Department of Adult Education and Lifelong Learning, \\ Faculty of Education, Obafemi Awolowo University, Ile-Ife, Nigeria
}

Doi:10.19044/esj.2021.v17n28p63

Submitted: 29 December 2020

Accepted: 06 July 2021

Published: 31 August 2021

\author{
Copyright 2021 Author(s) \\ Under Creative Commons BY-NC-ND \\ 4.0 OPEN ACCESS
}

Cite As:

Bamgbopa A. B. \& Babalola A. C. (2021). Juxtaposing Physical and Recreational Activities with Satisfaction with Life - A Case Study of Female Academics in Obafemi Awolowo University, Nigeria. European Scientific Journal, ESJ, 17 (28), 63.

https://doi.org/10.19044/esj.2021.v17n28p63

\begin{abstract}
This study was designed to assess the level of involvement of female academics in physical and recreational activities. It determined the life satisfaction status of female academics. It also ascertained the influence of participation in physical and recreational activities on female academics' satisfaction with life in Obafemi Awolowo University, Ile-Ife. The study adopted descriptive survey research design. The population of the study comprised all the 361 female academic staff members of all the 13 faculties in Obafemi Awolowo University Ile-Ile, Osun State, Nigeria. This study adopted primary data collection using well structured designed questionnaire. A sample of 182 respondents was selected using a simple random sampling technique, where 14 female lecturers were randomly selected from each of the 13 faculties with respect to their departments. A self-designed questionnaire was used to collect data. The results revealed that the female academics were passively involved in physical and recreational activities and that their participation in physical and recreational activities have influenced their satisfaction with life greatly. The study concluded that physical and recreational activities had significant positive influence on satisfaction with life in respect to the subjects of the study.
\end{abstract}

Keywords: Physical and Recreational Activities; Satisfaction with Life, Female Academics 


\section{Introduction}

The human body cannot function appropriately and may eventually fail if the required levels of physical activity are not met. Insufficient physical activity has been identified to be one of the topmost risk factors for noncommunicable diseases, which have also been linked with negative mental health and quality of life. One of the several explanations for degenerative well-being status is aging process which is significant to the adult population. This is referred to as 'the accumulated effect of living and may reduce the organism's adaptive capacity. The process of ageing, especially in the middle age, produces a decrease in some organic functions of the body. These include the elastic properties of tissues, cells of the nervous system, the number of normally functioning cells and oxygen utilisation. Others include the amount of blood pumped by the heart under resting conditions, the amount of air expired by the lungs and the excretion of hormones. These changes affect both individual organs and the collective ability of the whole system, which results in decreased physical ability and may result eventually in death (Guthold, Stevens, Riley, and Bull, 2018; WHO, 2013; Jegede, 2015). To aid the quality of life of the adult population, there are innumerable physical activity recommendations for the well-being of the adult in response to the need to provide aid to aging populace for successful aging, keeping the body in good shape and aiding the life satisfaction of individuals. Therefore, engaging in recreational activities that include physical activity assist the aging population lead independent and satisfied lives as they remain flexible and mobile as well as aiding their cognitive abilities (State of California Resources Agency, 2005).

Physical activity is conceived as any form of body movement that substantially increases the outflow of energy over the resting level. This can be in form of any bodily movement or exercise that requires energy expenditure. Exercise, which is a form of physical activity, can be defined as a planned, controlled and repetitive physical activity. Recreation then is supposed to refresh the mind, body and spirit through play and relaxation which can take many forms, from walking, cycling, and listening to music, to fitness sessions, yoga exercises, family outings and so on. To Umeasiegbu (2012), "recreation serves many purposes but the essential element relevant remains the tremendous contributions it makes to human health and wellbeing". These benefits according to Jarden (2011) include survival; the physical, health, mental and psychosocial well-being.

In the same vein, as reviewed in The British Columbia Centre of Excellence for Women's Health (1999) health delivery agencies have found physical activity and recreational-sports to be extremely important components of the everyday life of girls and women. Consequently, globally, there is growing consciousness of gender specific health issues and the need 
to programme specifically for gender. Physical activity recommendation for the well-being of adult women by the World Health Organisation (2010) can be seen as a response to the health and well-being demands of adults as they age, thus providing aids to their aging process for successful aging, keeping the body in good shape which conversely enhances the satisfaction with life.

The benefits of physical and recreation activities are numerous and innumerable. For instance, it can reduce the risk of cardiovascular diseases, diabetes, colon and breast cancer, and depression. Moreover, adequate levels of physical activity will decrease the risk of a hip or vertebral fracture and help control weight. Physical and recreational activity also plays important roles in the promotion of health, the prevention of disease conditions, the rehabilitation from disease, and the management of other risk factors, for positive health and for cardiopulmonary fitness and bone density, women's increased body image satisfaction through physical activity. In addition, it has a beneficial effect on mood, cognitive functioning and psychological well-being, decrease in levels of anxiety, depression, and psychological stress. It supports the development of a positive self-concept and contributes to general health, maintains functional capacity and sustains a positive quality of life into old age (Reid et al, 2000; Dyck, McKay, and Frisby, 2000; Umeasiegbu, 2012).

Health has been defined as the state of complete physical, mental and social well-being and not merely the absence of disease or infirmity. Health comprises of Physical health, Social health and Mental health. Physical health entails the evaluation of a living organism's overall condition at a given time. It refers to how well individuals' body functions as diet, hygiene, exercise, rest, disease, substances, environment, technology, and so on. These are essential factors that influence physical health conditions of the homo-sapiens. Social health on the other hand refers to the way an individual interacts, socializes, and gets along with other people including reacting to new environment, while mental health and emotional health addresses individuals' ability to accept themselves and others, acclimatise, manage emotions, and deal with the demands and challenges they encounter in life. Besides, the word recreation, irrespective of its various definitions, has been regarded as socially acceptable activities in which individuals engage freely at leisure hours. These activities are said to be capable of enhancing and developing the physical, social, mental and psychological well-being of participants engaging in them and such activities are characteristically voluntary, purposeful, pleasurable and satisfying (WHO 2016).

The noticed rising health care expenses have however prompted health care practitioners to search for programme choices that will reduce costs without impairing health delivery. Physical and recreational activity now fits beyond being supplementary (The British Columbia Centre of Excellence for Women's Health, 1999). Reid, Dyck, McKay, \& Frisby (2000) in a study to 
understand the relationship between the health of girls and women and physical activity found out that those regular physical activities are supported for positive health and for cardiopulmonary fitness and bone density. Their research concerns were based on rate of recurrence and importance to the health of girls and women; eating disorders, smoking and drug rehabilitation, cardiovascular disease and high blood pressure, osteoporosis, estrogensrelated cancers, menopausal symptoms, fibromyalgia and chronic fatigue syndrome, psychosocial health and well-being - taking account of stress, anxiety, depression, premenstrual syndrome, self-efficacy, mood state, cognitive functioning, self-esteem, well-being and quality of life. Physical and recreational activity according to this evaluation plays significant roles in the promotion of health, prevention of disease conditions, treatment and rehabilitation from disease, and in the management of other risk factors. However, several studies have suggested that physical activeness has a little effect of improving women's body image concerns, Reid et al, (2000) positioned that scores of recent searches have pointed to physical activity as a vital tool for increasing women's body image satisfaction. The effect of these activities more extends to older women as habitual physical activity is found to be helpful in maintaining functional capacity and sustaining positive quality of life into old age WHO (2016).

Reid et al (2000) further concluded that physical activity has a positive effect on mood, cognitive functioning and psychological well-being and that exercise is also connected to reduction of the levels of depression, anxiety, and psychological stress; which is capable of improving negative mood, premenstrual syndrome for women and girls as well as that it supports the development of positive self-concept and overall health. Physical activity is highly significant to overall well-being, functional capacity and autonomy. Consequently, there is positive indication that positive increase levels of physical exercise have positive effect on health and can prevent diseases and death. Women aged 65-80 who engage in physical exercise have been found to rely less on doctors and medication, and are more likely to try to maintain their good health through sports and positive feelings about their body. It has been reported that exercise helps them to reduce stress levels and anxiety about the future, keep fit and avoid health problems (WHO, 2016).

Health and well-being literature and research findings are also in clear agreement that the physical and recreational activities are beneficial to the subjective well-being of all humans as requirements to aiding individuals' life satisfaction and survival; such benefits include the physical, health, mental and psychosocial well-being (Jarden, 2011). On the other hand, if these requirements are not met, the human body cannot function properly and will ultimately fail. One of the several explanations for degenerative well-being status is aging process which is significant to the adult population. This is 
referred to as 'the accumulated effect of living, and according to Jegede (2015) may reduce the organism's adaptive capacity. Insufficient physical activity is a leading risk factor for non-communicable diseases, and has a negative effect on mental health and quality of life (Guthold, Stevens, Riley, and Bull, 2018). To aid the quality of life of the adult population, there are innumerable physical activity recommendations for the well-being of adult in response to the need to provide aid to aging populace for successful aging, keeping the body in good shape and aiding the life satisfaction of individuals.

The physical activity recommendation for the well-being of adult women is believed to be a response to the health and well-being demands of adults as they age, thus providing aids to their aging process for successful aging, keeping the body in good shape and their satisfaction with life. Having a mental health problem can put us at even higher risk of developing serious physical health problems than other people. People with mental health problem are twice as likely to die from heart disease; four times as likely to die from respiratory disease on average, likely to die between 10 and 17 years earlier than the general population. (MIND, n.d.).

According to Michaelson, Mahony \& Schifferes (2012),

Well-being can be understood as how people feel and how they function, both on a personal and a social level, and how they evaluate their lives as a whole. To break this down, how people feel refers to emotions such as happiness or anxiety. How people function refers to things such as their sense of competence or their sense of being connected to those around them. How people evaluate their life as a whole is captured in their satisfaction with their lives, or how they rate their lives in comparison with the best possible life.

Delineating satisfaction with life - a component of subjective wellbeing which is itself a component of well-being however, is fundamental. The subjective well-being includes different parts such as happiness, cognitive, total evaluation or assessment of an individual's life, satisfaction, positive emotions such as being joyous and proud and negative emotions such as pain and anxiety in appreciation of people's lives (Stone, 2012). Tremblay, Inman and Willms (2000) also posited that females and males who in comparison with their counterparts were more physically active had evidence of higher levels of self-esteem. Michaelson, Mahony and Schifferes (2012) described life satisfaction as positive assessment of one's overall life, in lieu of the results of the questions as regards satisfaction and life assessment.

The Satisfaction with Life Scale is a five-item measure that assesses an individual's global judgment of life satisfaction as a whole (Jarden, 2011). This Satisfaction with Life Scale was adapted for this study: Satisfaction with 
Life Scale for the Subjective Well-being. The Satisfaction with Life Scale (SWLS) was developed for the purpose of assessing the respondent's satisfaction in life as a whole:

The scale does not assess satisfaction with life domains such as health or finances but allows subjects to integrate and weigh these domains in whatever way they choose. Normative data are presented for the scale, which shows good convergent validity with other scales and with other types of assessments of subjective wellbeing. Life satisfaction as assessed by the SWLS shows a degree of temporal stability (e.g., 54 for 4 years), yet the SWLS has shown sufficient sensitivity to be potentially valuable to detect change in life satisfaction during the course of clinical intervention. Further, the scale shows discriminant validity from emotional well-being measures. The SWLS is recommended as a complement to scales that focus on psychopathology or emotional wellbeing because it assesses an individuals' conscious evaluative judgment of his or her life by using the person's own criteria.

The subjective well-being focuses on different aspects such as happiness, satisfaction, positive emotions such as joy and pride, and negative emotions such as pain and worry and cognitive evaluations of individuals' general life (Stone, 2012). Stemming from the study of psychological wellbeing, it encompasses distinguishing, and separately evaluating emotional and cognitive elements. Diener, Oishi, and Lucas (2003), address the distinctions which are to be entirely incorporated into the Subjective Well-being concept. They were of the opinion that both the current emotional status and the more abstract evaluation of the degree of satisfaction with life should be duly considered. At the same time, the subjective well-being paradigm adopted from Jarden's (2011) Satisfaction with Life Scale and Huppert (2009) were partially modified to evaluate the judgmental well-being, which is translated to the life satisfaction status of the participants.

The relevance and effect of Physical activities, recreation and bodily exercise is worldwide known and so much has been done by world health and well-being concerned organisations funding researches, making findings, reviews, write-ups and awareness to educate and promote such activities among nations on the effect of engaging and not engaging in physical and 
recreational activities, meeting up with the set requirement for daily and weekly physical activity for all category of human by World Health Organisation. The expected consequence includes reducing the chances of mortality associated with cardiovascular disease among others. Nevile, Hara and Milat (2009) established that $60 \%$ of the world's population does not meet the recommended level of physical activity. WHO in 2013 also, documented physical inactivity as the fourth principal risk factor for human death globally with an estimation of 3.2 million deaths throughout the world. More so, GilesCorti, Foster, Shilton and Falconer's studies in 2010 revealed that worldwide, $60 \%$ of adults are insufficiently active; and Dumith et al (2011) found that $80 \%$ occurrence of physical inactivity in the world was higher among women. Moreover, Guthold, Stevens, Riley, and Bull in 2018 ascertained that $96 \%$ of the world's population are insufficiently active.

Obafemi Awolowo University Ile-Ife interestingly has one of the best sporting and recreational facility situated in the most noticeable location of the institution, where countless physical and recreational activity are done on a daily basis; and a Staff Club to complement the possible demand of leisure and recreation among staff members of the institution. As a matter of fact, there is a special annual recreational activity programme for university staff members in Nigeria tagged "Staff Games", where staff members of all institutions in Nigeria participate competitively. However, unlike other participating institutions, it has been observed that none of the female academic and non-academic staff members of the university were present by any means for the past four seasons of the of the event. Another event is the "Triangular Games" which includes the University of Lagos, University of Ibadan and Obafemi Awolowo University Ile-Ife (O.A.U.), where a female staff member of the University of Lagos competed against the participating men and claimed the first position in a number of editions in table tennis, but no female representative from O.A.U. participated. More so, a very few numbers of the female academic staff members' population were noticed jogging or doing brisk-walking regularly on the "Road 1" of the institution when compared to their male counterparts.

The researchers observed the number of female staff members of the institution's participation compared to their male counterparts in recreational programmes and in inter-universities sporting activities for over two years. The attendance and participation of female staff member of the institution in recreational and physical activity programmes mentioned earlier is low. More so, some female lecturers have the characteristics of individuals coping with ailments such as obesity, arthritis, overweight and other physical and health issues which can affect their psychosocial well-being. Surprisingly the prefield observation of the researcher showed that three of the three academic staff members of one of the departments saddled with the educational and 
social impartation of physical health knowledge and practices were observed to have physical health issues such as obesity, arthritis and so on. Also, some female academic staff members under the age of 50 in some faculties were observed to be overweight or obese; even as many were seen showing signs of difficulty while climbing the stairs or showing signs of serious tiredness and discomfort.

The participation of the female academic staff members in physical and recreational activities, judging from the result of the researcher's preresearch observation and pilot study is disquietingly. In as much as the satisfaction with life (subjective well-being) is linked with physical health and physical activity, and it is difficult to ascertain whether the female academic staff members of Obafemi Awolowo University Ile-Ife really engage in required level of activity for well-being, for some reasons that might be gender-based or personal. A high level of participation or personal monitoring of physical well-being is a possible way out of aging and cardiovascular related difficulties. The researcher observed that the physiological need even on the hierarchy of needs of Abraham Marslow is highly important because it would contribute to the health and well-being of female adults, especially in the study area. Thus, it is necessary to determine the extent of involvement of the female adult members of staff of Obafemi Awolowo University in physical and recreational activities, and how beneficial this involvement could be and might have been to their general well-being. However, providing evidencebased information on the level of physical activity among them and establishing the impact of their participation on their satisfaction among them are very significant, hence, this study.

The specific objectives of the study are to:

i. assess the level of involvement of female academics in physical and recreational activities;

ii. determine the life satisfaction status of female academics who participate in physical and recreational activities in Obafemi Awolowo University; and

iii. ascertain the influence of participation in physical and recreational activities on female academics' satisfaction with life in Obafemi Awolowo University.

\section{Research Questions}

i. What is the level of involvement of female academics in physical and recreational activities?

ii. What is the life satisfaction status of female academics who participate in physical and recreational activities in Obafemi Awolowo University Ile-Ife? 
iii. What is the influence of participation in physical and recreational activities on female academics' satisfaction with life in Obafemi Awolowo University Ile-Ife?

\section{Methodology}

The data that are relevant to answering the questions raised in this chapter were extracted from a recent research work among female academics in Obafemi Awolowo university entitled "A Study of Self-Directed Learning, Physical and Recreational Activities on Satisfaction with Life of Female Academics in Obafemi Awolowo University, Ile-Ife."

This study adopted the descriptive survey design. The population of the study comprised all the 361 female academic staff members of all the 13 faculties in Obafemi Awolowo University Ile-Ile, Osun State, Nigeria. The eligible respondents still in the service are female academic staff members of the university. An assessment of physical and recreational activities on the satisfaction with Life of female academic staff was considered significant based on the fact that the study provided empirical information and raised more awareness among the staff of the institution on the beneficial effect of engaging in physical and recreational activities. This study adopted primary data collection using well structured designed questionnaire and was complemented with in-depth interview. The sample size was determined using a simplified formula for proportions developed by Yamane (1967:886). It provided a simplified formula to calculate sample sizes and gave room for a 95\% confidence level and 5\% level of precision.

Therefore, a sample of 182 (i.e. 52\% of the total population) respondents was selected using a simple random sampling techniques, where 14 female lecturers were randomly selected from each of the 13 faculties with respect to their departments giving every academic staff an opportunity to be selected.

A self-designed questionnaire titled "Physical and Recreational Activities and Satisfaction with Life Questionnaire (PRASLQ)" was used to collect data for the study. Pretesting of the questionnaire was carried out among 20 female academic staff members of Obafemi Awolowo University Ile-Ife who would not be part of the final testing. This was done to ensure that the respondents would understand the items and to measure the reliability (internal consistency) of the scales in the questionnaire. Data collected were analysed using Statistical Package for the Social Sciences (SPSS).

\section{Results}

\section{Socio-demographic characteristics of respondents}

This section presents the basic socio-demographic characteristics of respondents. This includes the age group, marital status, educational 
qualification level, religion; number of children, weight and height of the respondents.

Table 1: Percentage distribution of background characteristics

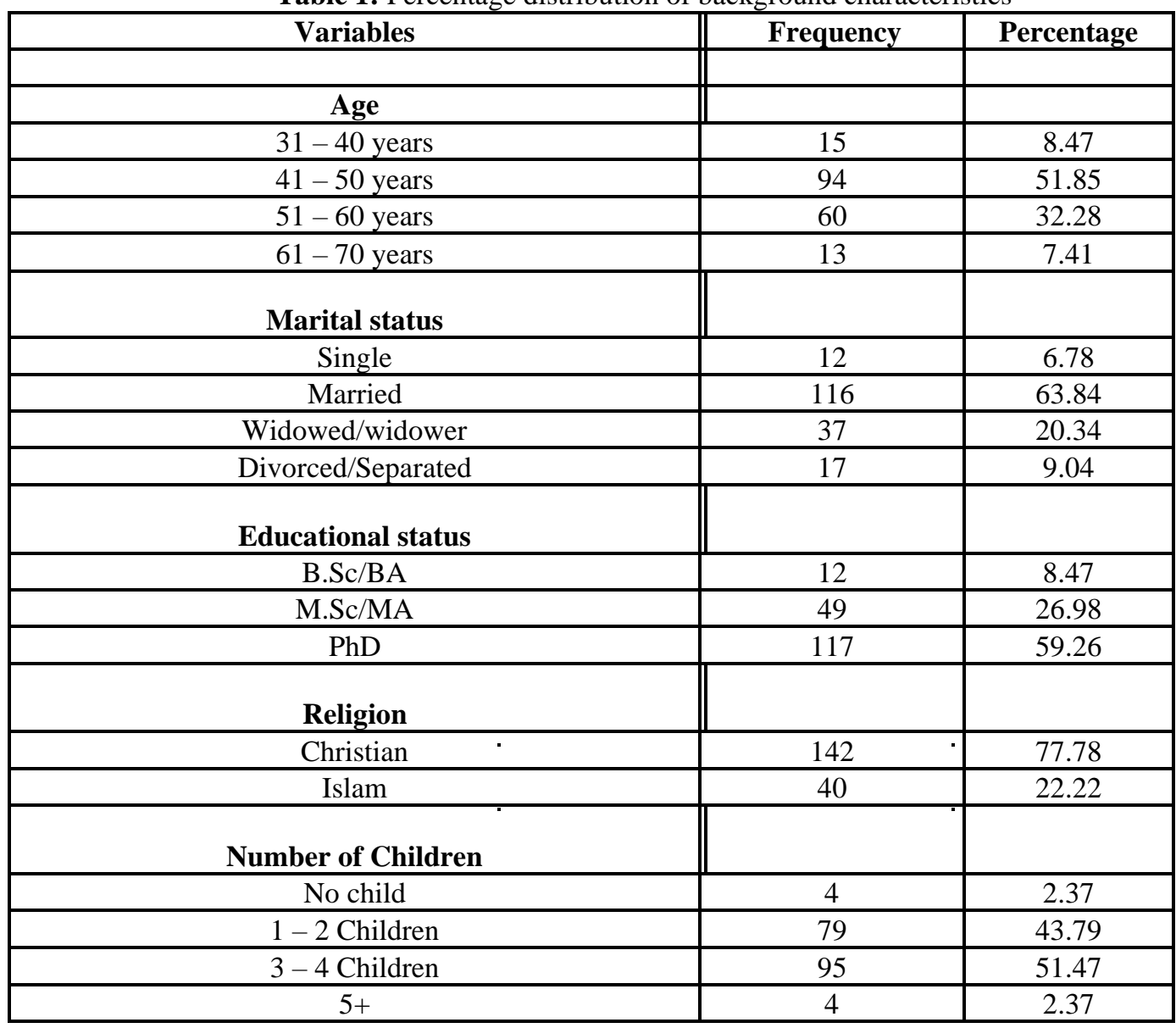

Source: Field Work (2018)

Table 2: Percentage distribution of respondent by weight

\begin{tabular}{|c|c|c|}
\hline Weight & Frequency $\mathbf{( N = 1 8 2 )}$ & Percentage \\
\hline Less than 50kg & 18 & $\mathbf{1 0 . 0}$ \\
\hline $\mathbf{5 0}-\mathbf{5 9 k g}$ & 58 & $\mathbf{3 1 . 7}$ \\
\hline $\mathbf{6 0}-\mathbf{6 9 k g}$ & 59 & $\mathbf{3 2 . 5}$ \\
\hline 70kg and above & 47 & $\mathbf{2 5 . 8}$ \\
\hline
\end{tabular}




\section{Research Question 1: What is the level of involvement of female academics in physical and recreational activities?}

Table 3: Engagement of female academics in sports, fitness and recreational activities

\begin{tabular}{|c|c|c|c|c|c|}
\hline Activities & $\begin{array}{c}\text { S. Agree } \\
(\%)\end{array}$ & $\begin{array}{l}\text { Agree } \\
(\%)\end{array}$ & $\begin{array}{c}\text { Disagree } \\
(\%)^{.}\end{array}$ & $\begin{array}{r}\text { S. disagree } \\
(\%)\end{array}$ & $\begin{array}{c}\text { Total } \\
(\%)\end{array}$ \\
\hline $\begin{array}{l}\text { I do vigorous-intensity sports, fitness or } \\
\text { recreational (leisure) activities that cause } \\
\text { large increase in breathing or heart rate } \\
\text { like running, jogging, swimming, aerobics, } \\
\text { exercising on the treadmill machine etc for } \\
\text { at least } 10 \text { minutes continuously. }\end{array}$ & $\begin{array}{c}109 \\
(60.2)\end{array}$ & $\begin{array}{c}32 \\
(17.7)\end{array}$ & $\begin{array}{c}36 \\
(19.9)\end{array}$ & $4(2.21)$ & $\begin{array}{c}182 \\
(100.0)\end{array}$ \\
\hline $\begin{array}{l}\text { In a week, I do vigorous intensity sports, } \\
\text { fitness or recreational (leisure) activities. }\end{array}$ & $\begin{array}{c}112 \\
(61.1)\end{array}$ & $\begin{array}{c}35 \\
(19.5)\end{array}$ & $\begin{array}{c}31 \\
(17.3)\end{array}$ & $4(2.2)$ & $\begin{array}{c}182 \\
(100.0)\end{array}$ \\
\hline
\end{tabular}

Source: Field Work (2018)

Table 3 shows engagement of female academics in sports, fitness and recreational activities. It can be observed that high proportion $60.0 \%$ strongly agreed to be engaged in vigorous-intensity sports, fitness or recreational (leisure) activities that cause large increase in breathing or heart rate like running, jogging, swimming, aerobics, exercising on the treadmill machine, etc for at least 10 minutes.

Table 4: Distribution of respondents by level of involvement on recreational activities in a typical week

\begin{tabular}{|l|l|l|l|l|}
\hline Recreational activities & $\begin{array}{l}\text { Highly } \\
\text { active }\end{array}$ & $\begin{array}{l}\text { Moderately } \\
\text { active }\end{array}$ & $\begin{array}{l}\text { Less } \\
\text { active }\end{array}$ & Total (\%) \\
\hline $\begin{array}{l}\text { Vigorous-intensity } \\
\text { activities }\end{array}$ & $10(5.8)$ & $27(14.7)$ & $145(79.6)$ & $\mathbf{1 8 2 ( 1 0 0 . 0 )}$ \\
\hline $\begin{array}{l}\text { Moderate-intensity } \\
\text { activities }\end{array}$ & $138(75.7)$ & $29(15.9)$ & $15(8.5)$ & $\mathbf{1 8 2 ( 1 0 0 . 0 )}$ \\
\hline Walking/riding bicycle & $126(69.3)$ & $38(20.6)$ & $18(10.0)$ & $\mathbf{1 8 2 ( 1 0 0 . 0 )}$ \\
\hline Vigorous-intensity sport & $142(77.8)$ & $25(13.8)$ & $15(8.5)$ & $\mathbf{1 8 2 ( 1 0 0 . 0 )}$ \\
\hline
\end{tabular}

Table 4 presents the length of time spent doing vigorous-intensity, moderate-intensity, walking or riding bicycle and vigorous-intensity sports, fitness or recreational activities at work on a typical day. For those who engaged in any of these activities for less than 10 minutes per day were considered "less active" while those who observed it between 10-30 minutes were considered "moderately active" and those who observed many of the activities were considered "highly active". It can be observed that majority (79.6\%) of respondents were highly active doing vigorous-intensity activities such as carrying or lifting heavy loads, walking, gesticulating while talking 
followed by $77.8 \%$ of those engaged in vigorous-intensity sports, fitness or recreational activities that cause large increase in breathing or heart rate such as running, jogging, swimming, aerobics, exercising on the treadmill machine, yoga, playing; lawn tennis, table tennis, volleyball, badminton, football while $75.7 \%$ engaged in moderate-intensity activities that cause small increases in breathing or heart rate such as brisk walking or carrying light loads and 69.3\% engaged in walking or riding bicycle for tour on a typical day. For moderately active respondents, $20.6 \%$ engaged in walking or riding bicycle followed by $15.9 \%$ in moderate-intensity activities, $14.7 \%$ engaged in vigorous-intensity activities and $13.7 \%$ in vigorously-intensity sports, fitness or recreational activities. $10.1 \%$ walking or riding bicycle, $8.5 \%$ moderate-intensity and vigorously-intensity sports, fitness or recreational activities and 5.8\% vigorous-intensity activities) were less active in length of time spent doing these activities.

\section{Research Questions 2: What is the life satisfaction status of female academics who participate in physical and recreational activities in Obafemi Awolowo University Ile-Ife?}

Table 5: Life satisfaction status of female academics in Obafemi Awolowo University

\begin{tabular}{|c|c|c|c|c|}
\hline Question Statements & $\begin{array}{l}\text { Low } \\
\text { satisfaction } \\
(\%)\end{array}$ & $\begin{array}{l}\text { Moderately } \\
\text { satisfied }(\%)\end{array}$ & $\begin{array}{l}\text { Highly } \\
\text { satisfied } \\
(\%)\end{array}$ & Total (\%) \\
\hline $\begin{array}{l}\text { How satisfied are you with your health } \\
\text { and well-being? }\end{array}$ & $4(2.2)$ & $24(13.3)$ & $154(84.5)$ & $182(100.0)$ \\
\hline $\begin{array}{l}\text { How satisfied are your relationships with } \\
\text { friends? }\end{array}$ & $7(3.9)$ & $40(22.1)$ & $135(74.0)$ & $182(100.0)$ \\
\hline $\begin{array}{l}\text { How satisfied are you with your } \\
\text { relationship with family, including } \\
\text { spouse/partner? }\end{array}$ & $0(0.00)$ & $32(17.1)$ & $150(82.9)$ & $182(100.0)$ \\
\hline $\begin{array}{l}\text { How satisfied are you with your physical } \\
\text { health? }\end{array}$ & 5. $(2.7)$ & $35(19.2)$ & $142(79.1)$ & $182(100.0)$ \\
\hline $\begin{array}{l}\text { How satisfied are you with your life these } \\
\text { days? }\end{array}$ & $9(4.9)$ & $28(15.4)$ & $145(79.7)$ & $182(100.0)$ \\
\hline $\begin{array}{l}\text { How worried are you with everything that } \\
\text { is happening in the world these days? }\end{array}$ & $21(12.1)$ & 98.(56.7) & 54. (31.2) & $182(100.0)$ \\
\hline $\begin{array}{l}\text { How optimistic do you feel about the next } \\
12 \text { months? }\end{array}$ & $3(1.7)$ & $23(13.3)$ & $147(85.0)$ & $182(100)$. \\
\hline $\begin{array}{l}\text { To what extent do you feel that the things } \\
\text { you do in your life are worthwhile? }\end{array}$ & $5(1.7)$ & $8(4.5)$ & $169(92.8)$ & $182(100.0)$ \\
\hline $\begin{array}{l}\text { To what extent do you feel that the } \\
\text { things you do in your life have purpose? }\end{array}$ & $3(1.7)$ & $8(4.5)$ & $171(93.8)$ & $182(100.0)$ \\
\hline
\end{tabular}


Table 6: Level of satisfaction with life of female academics in Obafemi Awolowo University

\begin{tabular}{|l|l|l|}
\hline Level of satisfaction & Frequency & Percentage \\
\hline High satisfaction & 83 & 45.5 \\
\hline Moderate satisfaction & 74 & 40.6 \\
\hline Low satisfaction & 25 & 13.9 \\
\hline Total & 182 & 100 \\
\hline
\end{tabular}

Source: Field Work (2018)

Table 6 presents results of the life satisfaction status of female academics who participated in physical and recreational activities (PRA). The respondents claimed that there existed a great connection between doing physical and recreational activities and well-being. Physical and recreational activities were factors of satisfaction with life. Majority affirmed their satisfaction with health, stature and well-being all as a result of PRA. In fact, they planned to improve on the time they gave to physical and recreational activities. One of them was planning to go and register in a gym:

Research Questions 3: What is the influence of participation in physical and recreational activities on female academics' satisfaction with life in Obafemi Awolowo University Ile-Ife?

Table 7: Association between participation in physical and recreational activities on female academics' satisfaction with life

\begin{tabular}{|c|c|c|c|c|c|c|}
\hline \multirow[t]{2}{*}{ Variable } & \multicolumn{6}{|c|}{ Level of satisfaction with life } \\
\hline & Low & Moderate & High & Total & $\chi^{2}$ & p-value \\
\hline \multicolumn{7}{|c|}{ Overweight } \\
\hline Yes & 15 (11.9) & $56(45.2)$ & $54(42.9)$ & $\begin{array}{c}125 \\
(100.0)\end{array}$ & 3.256 & 0.046 \\
\hline No & $10(17.5)$ & $18(31.6)$ & $29(50.9)$ & $57(100.0)$ & & \\
\hline \multicolumn{7}{|c|}{ Sleeplessness } \\
\hline Yes & $10(8.9)$ & $41(37.2)$ & $61(53.9)$ & $\begin{array}{c}112 \\
(100.0)\end{array}$ & 10.904 & 0.014 \\
\hline No & $15(21.4)$ & $33(47.1)$ & $22(31.4)$ & $70(100.0)$ & & \\
\hline \multicolumn{7}{|c|}{ High blood pressure } \\
\hline Yes & $16(16.2)$ & $34(32.4)$ & $54(51.4)$ & $\begin{array}{c}104 \\
(100.0) \\
\end{array}$ & 7.605 & 0.022 \\
\hline No & $8(10.3)$ & $41(52.6)$ & $29(37.2)$ & $78(10.00)$ & & \\
\hline \multicolumn{7}{|c|}{ Sedentary (inactiveness) } \\
\hline Yes & $25(13.7)$ & $54(41.5)$ & $57(44.4)$ & $\begin{array}{c}129 \\
(100.0)\end{array}$ & 0.099 & 0.952 \\
\hline No & $7(13.2)$ & $21(39.6)$ & $25(47.2)$ & $53(100.0)$ & & \\
\hline \multicolumn{7}{|l|}{ Arthritis } \\
\hline Yes & $17(14.0)$ & $53(43.8)$ & $50(42.2)$ & $\begin{array}{c}120 \\
(100.0)\end{array}$ & 1.5411 & 0.463 \\
\hline No & $8(12.9)$ & $22(35.5)$ & $32(51.6)$ & $62(100.0)$ & & \\
\hline Menstrua & & & & & & \\
\hline
\end{tabular}




\begin{tabular}{|c|c|c|c|c|c|c|}
\hline Yes & $19(15.2)$ & $50(40.8)$ & $55(44.0)$ & $\begin{array}{c}124 \\
(100.0)\end{array}$ & 0.8466 & 0.655 \\
\hline No & $6(10.3)$ & $24(41.4)$ & $28(48.3)$ & $58(100.0)$ & & \\
\hline \multicolumn{7}{|c|}{ Physical change in body } \\
\hline Yes & $12(11.0)$ & $36(33.0)$ & $61(55.9)$ & $\begin{array}{c}109 \\
(100.0)\end{array}$ & 11.758 & 0.003 \\
\hline No & $13(17.8)$ & $38(52.1)$ & $22(30.1)$ & $73(100.0)$ & & \\
\hline \multicolumn{7}{|l|}{ Dizziness } \\
\hline Yes & $11(11.3)$ & $35(36.1)$ & $51(52.6)$ & $97(100.0)$ & 4.1525 & 0.125 \\
\hline No & $14(16.5)$ & $39(45.8)$ & $32(37.7)$ & $85(100.0)$ & & \\
\hline \multicolumn{7}{|c|}{ Poor breath control } \\
\hline Yes & $8(8.7)$ & $35(38.0)$ & $49(53.3)$ & $92(100.0)$ & 6.145 & 0.039 \\
\hline No & $17(18.9)$ & $39(43.3)$ & $34(37.8)$ & $90(100.0)$ & & \\
\hline \multicolumn{7}{|l|}{ Loss of appetite } \\
\hline Yes & $17(15.0)$ & $37(32.7)$ & $59(52.2)$ & $\begin{array}{c}113 \\
(100.0)\end{array}$ & 7.818 & 0.020 \\
\hline No & $8(11.6)$ & $37(53.6)$ & $24(34.8)$ & $69(100.0)$ & & \\
\hline \multicolumn{7}{|c|}{$\begin{array}{l}\text { Stiffness in certain part of } \\
\text { the body }\end{array}$} \\
\hline Yes & $13(18.6)$ & $27(38.6)$ & $30(42.9)$ & $70(100.0)$ & 2.246 & 0.035 \\
\hline No & $12(10.7)$ & $47(41.9)$ & $53(47.3)$ & $\begin{array}{c}112 \\
(100.0)\end{array}$ & & \\
\hline \multicolumn{7}{|l|}{ Tiredness } \\
\hline Yes & $8(11.9)$ & $28(41.8)$ & $31(46.3)$ & $67(100.0)$ & 0.293 & 0.864 \\
\hline No & $17(14.9)$ & $46(40.0)$ & $52(45.2)$ & $\begin{array}{c}115 \\
(100.0) \\
\end{array}$ & & \\
\hline \multicolumn{7}{|c|}{ Emotional imbalance } \\
\hline Yes & 4. $(7.5)$ & $24(45.3)$ & $25(47.2)$ & $53(100.0)$ & 2.518 & 0.284 \\
\hline No & $21(16.3)$ & $50(38.8)$ & $58(44.9)$ & $\begin{array}{c}129 \\
(100.0)\end{array}$ & & \\
\hline \multicolumn{7}{|l|}{$\begin{array}{l}\text { Cardiovascular } \\
\text { abnormalities }\end{array}$} \\
\hline Yes & $8(13.1)$ & $34(39.3)$ & $29(47.5)$ & $61(100.0)$ & 0.1403 & 0.932 \\
\hline No & $17(14.1)$ & $50(41.3)$ & $54(44.6)$ & $\begin{array}{c}121 \\
(100.0)\end{array}$ & & \\
\hline
\end{tabular}

Source: Field Work (2018)

Table 7 shows the association between participation in physical and recreational activities on female academics' satisfaction with life. There is statistical significance association between Overweight with $\left(\chi^{2}=3.256\right.$; $\mathrm{p}=0.046)$, Sleeplessness $(\chi 2=10.904 ; \mathrm{p}=0.014)$, High blood pressure with $(\chi 2=7.605 ; \mathrm{p}=0.022)$, Physical change in the body with $(\chi 2=11.758 ; \mathrm{p}=0.003)$, Poor breath control with $(\chi 2=6.145 ; \mathrm{p}=0.039)$, Loss of appetite with $(\chi 2=7.818 ; \mathrm{p}=0.020)$ and Stiffness in certain part of the body $\left(\chi^{2}=2.246\right.$; $\mathrm{p}=0.035$ ). It can be observed that, there exists significant association among overweight, sleeplessness, high blood pressure, physical change in the body, 
poor breath control, loss of appetite and stiffness as their $(\mathrm{p}<0.05)$. The results simply mean that, in the course of female academics participating in physical and recreational activities, these issues were corrected and consequently affected their satisfaction with life.

Table 8: Remark on health and well-being status in the last 12 months

\begin{tabular}{|l|l|l|l|}
\hline & $\begin{array}{l}\text { Perfect } \\
(\%)\end{array}$ & Satisfactory (\%) & Manageable (\%) \\
\hline $\begin{array}{l}\text { My level of physical fitness } \\
\text { in comparison with others of } \\
\text { your age }\end{array}$ & $68(37.72)$ & $111(57.49)$ & $\mathbf{1 3 ( 4 . 7 9 )}$ \\
\hline $\begin{array}{l}\text { My quality of life in relation to } \\
\text { your psychological and } \\
\text { emotional well- being }\end{array}$ & $51(27.54)$ & $122(70.06)$ & $\mathbf{9 ( 2 . 4 0 )}$ \\
\hline
\end{tabular}

Source: Field Work (2018)

More so, the joint influence of respondents' participation in physical and recreational activities as revealed in table 8 shows respondents' remark on health and well-being status in the last 12 months. $57.49 \%$ of female academics claimed their level of physical fitness in comparison with others of their ages were satisfactory followed by $37.72 \%$ who claimed to be perfect and a few of approximately 5\% who claimed to be manageable. Approximately $70 \%$ claimed their quality of life in relation to their psychological and emotional well-being were satisfactory, $28 \%$ perfect and $2.4 \%$ claimed manageable. However, they were not benefiting maximally as they were supposed to because of their work schedule and other reasons:

\section{Discussion of Findings}

From the findings of this study, it can be established that the female academics who participate in physical and recreational activities are more satisfied with their lives. This is supported in literature by Abdulahhi and Fauzee's (2002) study cited in Umar (2011) that among the benefits gained from physical activities are improvements of the lung system by way of deepening a person's respiration as well as strengthening the heart's muscles and increasing its size; and that the influence of active lifestyle includes attractive looking and positive changes in moods and increase in self-esteem. In fact, the majority of the female academics displayed unimaginable knowledge of well-being enhancing physical activities despite not in the field of health and physical education, as they also claimed to be engaging and also are willing to create more time for physical and recreational engagement as soon as possible.

Consequently, the study found that participation in physical and recreational activities had enhanced satisfaction of the female academic staff members of Obafemi Awolowo University. The participants claimed to have 
overcome health and well-being challenges such as cardiovascular related difficulties, bad moods, tiredness, arthritis and so on, and that the activities had enhanced their life satisfaction status; which is in agreement with the position of Jarden (2011) that, physical and recreational activities were beneficial to the subjective well-being of all humans as requirements to aiding individuals' life satisfaction and survival; such benefits include the physical, health, mental and psychosocial well-being.

Furthermore, the influence of the activities according to the Centre for Women's Mental Health (1999) agrees with the above finding, where it posited that females engage in physical and recreational activities for various reasons and such reasons included, body image, coping with diseases, cardiovascular fitness, psychosocial well-being, mood improvement associated with Premenstrual Syndrome (PMS). Umar (2011) is of the opinion that participating in such activity is for the enhancement of body functions by the reactions of the skeletal muscles. Reid et al. (2000) further posited that physical activity had a beneficial effect on mood, cognitive functioning and psychological well-being; which had also been shown to be responsible for decrease in levels of anxiety, depression, and psychological stress, and linked with improving negative mood associated with PMS for women. The above finding thus clearly agree with Brown et al's study (2011) which concluded that a less active and more sedentary lifestyle on the other hand, increased the risk of premature death compared to leading an active lifestyle.

\section{Conclusion}

In conclusion, the majority of the respondents who were female academics in Obafemi Awolowo University confirmed that there was a huge connection between their participation in physical and recreational activities and satisfaction with life. Their engagements therefore had positive effect on their well-being and satisfaction with life; they were planning to create more time for themselves in order to maximally benefit as recommended for their well-being and satisfaction and those who created time to participate in PAR apparently appeared to be more satisfied with their quality of life.

\section{Recommendations}

i. There is the need to raise more awareness among the female academic staff members of the institutions and women generally on the beneficial effect of engaging in physical and recreational activities. This is necessary because the female academics who participate in physical and recreational activities are more satisfied with their lives.

ii. It is imperative that necessary information get to the population of study on the recommendation of the World Health Organization for the well-being 
for the female gender, especially the female academics that are usually supposed to be busy as per daily workplace and career requirements.

iii. There should also be a study on how physical and recreational activities are important to the health of both gender in higher institutions in Nigeria and the limiting factors for the female gender's participation should be investigated.

\section{References:}

1. Diener, E., Oishi, S., and Lucas R., (2003). Personality, Culture, and Subjective Well-being: Emotional and Cognitive Evaluations of Life. Annual review of psychology 2003: retrieved from annualreviews.org

2. Dumith, S., Hallal, P., Reis, R., and Kohl III, H. (2011). Worldwide prevalence of physical inactivity and its association with human development index in 76 countries. Journal of Preventive Medicine. Retrieved from sciencedirect.com.

3. Giles-Corti, B., Foster, S., Shilton, T., and Falconer R. (2010). The cobenefits for health of investing in active transportation. New South Wales public health bulletin 21 (6), 122-127, 2010: Retrieved from publish.csiro.au

4. Guthold, R., Stevens, G., Riley, L., and Bull, F. (2018). Worldwide trends in insufficient physical activity from 2001 to 2016: a pooled analysis of 358 population-based surveys with 1. 9 million participants. The Lancet Global Health 6 (10), e1077-e1086, 2018. Retrieved from sciencedirect.com

5. Huppert, F., (2009). Psychological Well-being: Evidence Regarding Its Causes and Consequences. Applied Psychology Health and Well-being Journal.

6. Jarden, A., (2011). Positive Psychological Assessment: A practical introduction to empirically validated research tools for measuring wellbeing. Retrieved from academia.edu

7. Jegede, O. (2015). What is Adult in Adult Education? Nigeria: University of Lagos Press \& Bookshop Ltd.

8. Michaelson J., Mahony S. and Schifferes J. (2012). Measuring Wellbeing: A Guide for Professioners (Center for Wellness). London: The New Economics Foundation.

9. Neville, L.M., O'Hara, B. \& Milat, A. Computer-tailored physical activity behavior change interventions targeting adults: a systematic review. Int $J$ Behav Nutr Phys Act 6, 30 (2009). https://doi.org/10.1186/1479-5868-6-30

10. Reid, C. Dyck, McKay, and Frisby, W. (2000). The health benefits of physical activity for girls and women. Literature review and recommendations for future research and policy.Vancouver, British Columbia: British Columbia Centre of Excellence for Women's Health.

11. State of California Resources Agency (2005). The Health and Social Benefits of Recreation the Health and Social Benefits of Recreation: An 
Element of the California Outdoor Recreation Planning Program. California: California State Parks. Retrieved from www.parks.ca.gov/planning.

12. Stone, A. (2012). Subjective Wellbeing Assessment for Survey Research. Department of Psychiatry and Behavioral Science. Stony Brook University: WHO Technical Meeting.

13. Tremblay, M. S., Inman, W. J. \& Willms, J. W. (2000). The Relationship between Physical Activity, Self-Esteem, and Academic Achievement in 12Year-Old Children. Pediatric exercise science, 12, 3 DOI: 10.1123/pes.12.3.312.

14. The British Centre of Excellence for Women's Health, (2000). The Health Benefits of Physical Activity for Girls and Women British Columbia. Canada: Albert Recreation and Parks Association

15. Umar, S. (2014). Perceived exercise benefits and Barriers among Staff and Students of Tertiary Institutions in Adamawa State. Nigeria: Med. Thesis published by the University of Nigeria Nsukka.

16. Umeasiegbu, G. and Nwankwo, C. (2012). Availability of Recreational Facilities for Psycho-Social and Mental Well-being of Adults in Anambra State Nigeria. Scholarlink Research Institute Journals (ISSN:2141-6990).

17. World Health Organization (2010). Global Recommendations on Physical Activity for Health. Switzerland:

18. WHO Press. Retrieved from https://www.who.int/dietphysicalactivity/global-PA-recs-2010.pdf

19. World Health Organisation 2013, "Non-communicable diseases and mental health". Retrieved from http://www.who.int/nmh/publications/9789241597418/en/

20. World Health Organization (2016). Women's health and well-being in Europe: beyond the mortality advantage. WHO Regional Office for Europe, Retrieved from https://apps.who.int/iris/bitstream/handle/10665/332324/9789289051910eng.pdf 